\title{
Tunicamycin enhances the suppressive effects of cisplatin on lung cancer growth through PTX3 glycosylation via $\mathrm{AKT} / \mathrm{NF}-\kappa \mathrm{B}$ signaling pathway
}

\author{
BULBUL AHMMED $^{1 *}$, MUHAMMAD NOMAN KHAN ${ }^{1,2^{*}}$, MUHAMMAD AZHAR NISAR $^{1}$, \\ SYLVANUS KAMPO $^{1}$, QIN ZHENG $^{1}$, YULIN LI ${ }^{1}$ and QIU YAN $^{1}$ \\ ${ }^{1}$ Department of Biochemistry and Molecular Biology, Liaoning Provincial Core Laboratory of Glycobiology \\ and Glycoengineering, Dalian Medical University, Dalian, Liaoning 116044, P.R. China; \\ ${ }^{2}$ Department of Physiology, University of Karachi, Karachi 75270, Pakistan
}

Received December 20, 2017; Accepted July 5, 2018

DOI: 10.3892/ijo.2018.4650

\begin{abstract}
Long pentraxin-3 (PTX3) is an inflammatory molecule related to cancer proliferation, invasion, and metastasis. Many studies have highlighted the significance of glycosylated molecules in immune modulation, inflammation and cancer progression. Moreover, aberrant glycosylation of cancer cells is linked to chemoresistance. This study aimed to develop effective therapeutic strategies for deglycosylation of PTX3 (dePTX3) in order to enhance chemosensitivity to cisplatin (Cis) in lung cancer treatment. The A549 and SPCA1 cells were used to determine the role of PTX3 glycosylation in lung cancer growth. Our results revealed that PTX3 was higher in both human lung cancer tissues and serum in comparison with control. Furthermore, we found that deglycosylated PTX3 (dePTX3) by tunicamycin (TM), which is N-glycan precursor biosynthesis blocker, and PNGase F significantly reduced the survival and migration of lung cancer cells. To further confirm this, we also generated glycosylation-site mutant of PTX3 (mPTX3) to characterize the loss of glyco-function. dePTX3 and TM enhanced the suppressive effects of Cis on lung cancer cell growth, migration and invasion compared to individual treatment. Treatment with a combination of TM and Cis significantly inactivated $\mathrm{AKT} / \mathrm{NF}-\kappa \mathrm{B}$ signaling pathway and
\end{abstract}

Correspondence to: Dr Qiu Yan, Department of Biochemistry and Molecular Biology, Liaoning Provincial Core Laboratory of Glycobiology and Glycoengineering, Dalian Medical University, Dalian, Liaoning 116044, P.R. China

E-mail: yanqiu63@126.com

${ }^{*}$ Contributed equally

Abbreviations: PTX3, pentraxin-3; dePTX3, deglycosylated PTX3; PNGase F, peptide N-glycosidase F; rhPTX3, recombinant human pentraxin-3; TM, tunicamycin; Cis, cisplatin

Key words: long pentraxin-3, glycosylation, tunicamycin, cisplatin, chemosensitivity induced apoptosis. In conclusion, these findings suggest that PTX3 is an important mediator of lung cancer progression, and dePTX3 by TM enhances the anticancer effects of Cis. The deglycosylation in chemotherapy may represent a potential novel therapeutic strategy against lung cancer.

\section{Introduction}

Lung cancer, the most common type of cancer worldwide, and non-small cell lung cancer (NSCLC), is the primary subtype, accounting for $80 \%$ of all new lung cancer cases $(1,2)$. Despite current advances in chemotherapy and molecular targeted therapy, the 5-year survival rate of patients with NSCLC remains $<15 \%$. Resistance to therapies in lung cancer is closely associated with the dysregulation of oncogenes or tumor suppressor genes, all of which involve changes in the biological characteristics of cancer cells, cell growth, apoptosis, migration, invasion, etc (3). Although cisplatin (Cis) has long been a cornerstone agent in anticancer chemotherapy (4), many cancer cells, including lung cancer, may develop and acquire the resistance to $\mathrm{Cis,}$ and other cancers are naturally resistance to this drug, which is an obstacle to successful chemotherapy (5). Furthermore, Cis cytotoxicity, such as nephrotoxicity and neurotoxicity, is a common side-effect of Cis (6). Therefore, novel therapeutic strategies for lung malignancies using combined agents with distinct molecular mechanisms are considered more promising for the enhanced therapeutic efficacy to improve the survival rate.

Human pentraxin-3 (PTX3) is a multimeric glycoprotein with eight subunits that comprise 381 amino acids (7). Among the different species, the primary sequence of PTX3 is highly conserved, sharing $92 \%$ of consensus amino acid residues between human and murine sequences, indicating strong evolutionary pressure to maintain its function/structure relationships (8). Human pentraxin-3 family is divided into long and short subfamilies. Similar to other members of the long pentraxin subfamily, PTX3 is constructed of a distinctive C-terminal domain, and N-terminal region with homology to short pentraxin, C-reactive protein (CRP) and serum amyloid P component (SAP) $(9,10)$. PTX3 is involved in the 
inflammatory process. The increased PTX3 was reported in chronic kidney diseases, endotoxin shock, sepsis and vasculitis (11). Furthermore, the level of PTX3 reflects the severity of inflammation. It is considered that tumorigenesis is an inflammation-related disease. An elevated PTX3 expression is noted in glioma, liposarcoma, prostate cancer, lung cancer and breast cancer (12-16). It is closely associated with cell proliferation, metastasis, pathological grading and drug sensitivity $(13,17,18)$.

The glycosylation of proteins is an important post-translational modification, and the resulting glycoproteins participate in a number of key biological processes, including cell growth, differentiation and immune modulation, etc (19). Altered glycosylation has been found in inflammatory diseases and many types of cancer (20-22). Recent advances in the evaluation of protein glycosylation and cell malignancy have gained the attention of many researchers, with the aim to treat cancer or other diseases with alterations in cellular glycosylation (23), and modifications in the glycan structures of proteins have been known to be an indicator of inflammation and carcinogenesis $(24,25)$. Alterations in N-linked oligosaccharides on tumor cell surfaces are associated with proliferative, migratory and invasive properties (26). Particularly, the C-terminal domain of PTX3 at Asn-220 has been identified as a single $\mathrm{N}$-linked glycosylation site that is completely occupied by complex oligosaccharides (7), generally fucosylated and sialylated bi-antennary sugars with a minor fraction of tri- and tetra-antennary glycans. Interestingly, the relative contents of bi-, tri- and tetra-antennary glycans, and the level of sialylation have been shown to be highly variable among PTX3 isolated from different cellular sources, suggesting that the glyco-moiety of PTX3 is involved in a number of biological activities (10). Based on three-dimensional models, PTX3 oligosaccharides interact with the polar and basic amino acids from the other proteins by surface (i.e., Arg332 and Glu252), typically through terminal residues of sialic acid (8). These types of interactions are forfeited when sialic acid is removed, and protein sites that are potentially relevant to ligand recognition and/or modification of the PTX3 tertiary/quaternary structure become attainable. Therefore, modifications in glycosylation have been investigated as potential biomarkers for both chronic inflammatory processes and cancer, associated with disease severity in certain conditions (23). These alterations in glycosylation are also known to regulate cell signaling and may contribute to disease pathogenesis.

Tunicamycin (TM) is used to inhibit N-linked oligosaccharide biosynthesis in cells (27). Existing reports indicate that disruption of $\mathrm{N}$-linked glycosylation inhibits downstream signaling pathways, suggesting that TM is an alternative therapeutic approach to reduce oncogenic signaling and drug resistance (25). TM has been demonstrated to enhance the susceptibility of lung cancer cells to therapy, sensitize resistant cancer cells to chemotherapy and to potentiate Cis-induced cytotoxicity in human head and neck carcinoma (28). TM has also been reported to decrease vascular endothelial growth factor (VEGF) expression in nude mice and to inhibit angiogenesis (29). These findings indicate that the TM-induced disruption of N-linked glycosylation has a considerable advantage in targeting multiple glycoproteins and sensitizing cancer cells to anticancer therapeutics.

The current study was designed to assess the significance of PTX3 deglycosylation in the suppression of human lung cancer. We examined PTX3 expression levels, which were increased in human lung cancer tissues and cells, and dePTX3 suppressed lung cancer cell proliferation and migration. We also found that the dePTX3 by TM enhanced the sensitivity of lung cancer cells to $\mathrm{Cis}$ through $\mathrm{AKT} / \mathrm{NF}-\kappa \mathrm{B}$ signaling pathway.

\section{Materials and methods}

Cell culture and human samples. Human lung cancer cell lines (A549 and H1299) were purchased from the American Type Culture Collection (ATCC) and SPCA1 cell line was purchased from the Cell Bank of Chinese Academy of Sciences (Shanghai, China). The cells were cultured in RPMI-1640 medium supplemented with $10 \%$ fetal bovine serum (FBS), $100 \mathrm{U} / \mathrm{ml}$ penicillin and $100 \mu \mathrm{g} / \mathrm{ml}$ streptomycin (Gibco Life Technologies/Thermo Fisher Scientific, Inc., Waltham, MA, USA) at $37^{\circ} \mathrm{C}$ in humidified air containing $5 \% \mathrm{CO}_{2}$. A total of 34 patients (28 males and 6 females) with third-grade lung cancer and 42 normal healthy patients ( 26 males and 16 females) with a mean age of 56 years were recruited (by lung biopsy or lobectomy) after obtaining informed consent. Lung tissues and serum samples were collected from January, 2015 to December, 2017. All lung cancer paraffin-embedded sections and lung cancer tissues were obtained at the First Affiliated Hospital of Dalian Medical University.

Reagents and antibodies. TM was purchased from Sigma-Aldrich (St. Louis, MO, USA) which was dissolved in DMSO. Cis and peptide N-glycosidase F (PNGase F) were purchased from Sigma-Aldrich. Cell Counting kit-8 (CCK-8) was obtained from Beyotime Biotechnology (Shanghai, China); recombinant human PTX3 (rhPTX3) (\#PROTP26022; Boster Biological Technology Co., Ltd., Fremont, CA); NF- $\kappa \mathrm{B}$ inhibitor (IKK-16), PI3K inhibitor (GDC0941), MEK1/2 inhibitor, (MEK162) were purchased from Selleck Chemicals (Shanghai, China). Antibodies against p-p65 (\#3033), p65 (\#8242), p-IKK (\#2078) and IKK (\#2682) were from Cell Signaling Technology (Danvers, MA, USA); MMP-9 (\#10375) was from Proteintech (Wuhan, China); antibodies against AKT (\#AA326), p-AKT (T308) (\#AA331) were from Beyotime Biotechnology; PTX3 (\#13797-1-AP), poly (ADP-ribose) polymerase (PARP) (\#AF-1657), cleaved PARP (\#AF-1567), Bcl2 (\#12789-1-AP), Bax (\#50599-2-Ig), proliferating cell nuclear antigen (PCNA) (\#24036-1-AP), HRP-conjugated anti-rabbit and anti-mouse antibodies and GAPDH (\#10494-1-AP, \#60004-1-Ig) antibodies were from Proteintech; HRP-conjugated goat anti-rabbit secondary antibody (ZSGB-BIO, Beijing, China).

Coomassie brilliant blue (CBB) staining. The concentrated CBB R-250 (\#20278; Thermo Fisher Scientific, Inc.) solution $[5 \%(\mathrm{w} / \mathrm{v})]$ was prepared in distilled water and stirred for more than $1 \mathrm{~h}$. The supernatant of the CBB solution, centrifuged at $7,000 \mathrm{x} g$ for $5 \mathrm{~min}$, was used to prepare the staining solution. The gels were soaked in the staining solution containing 
$0.1 \%(\mathrm{w} / \mathrm{v})$ CBB R-250, 50\% (v/v) methanol, and 10\% (v/v) acetic acid at room temperature for $4 \mathrm{~h}$. Subsequently, the CBB-stained gels were agitated in the de-staining solution containing $40 \%(\mathrm{v} / \mathrm{v})$ methanol and $10 \%(\mathrm{v} / \mathrm{v})$ acetic acid.

Immunohistochemistry. The excised tumor tissues were fixed in $5 \%$ formalin for $24 \mathrm{~h}$, embedded in paraffin and then sectioned ( $4 \mu \mathrm{m}$ thickness) in a standard manner. The sections were deparaffinized in xylene followed by a graded series of ethanol $(100,95,85$ and $70 \%)$, and rehydrated in phosphate-buffered solution, $\mathrm{pH}$ 7.5. The antibodies used for paraffin-embedded tissues were monoclonal rabbit anti-PTX3 antibody, (\#13797-1-AP; Proteintech). The primary antibodies were diluted (1:50) in PBS containing $3 \%$ bovine serum albumin (BSA). The sample slides were treated at $37^{\circ} \mathrm{C}$ for 30 min with blocking solution (8\% goat serum in PBS with $3 \%$ BSA) before the primary antibody was applied. Endogenous peroxidase was blocked by incubation with $3 \%$ hydrogen peroxide. Endogenous avidin and biotin were blocked using the Avidin/Biotin Blocking kit (SP-9000; ZSGB-BIO). Overnight incubation with the primary antibody was followed by incubation with the respective biotinylated secondary antibody, followed by the $\mathrm{ABC}$ reagent for signal amplification. Between the incubation steps, the slides were washed in TBS. 3,3'-diami-nobenzidine (DAB kit; ZLI-9017; ZSGB-BIO) was used to develop the color. The slides were counter-stained with hematoxylin, mounted in Kaisers Glycerinegelatine (Merck, Germany), and covered with a coverslip. Dark yellowish brown stain indicated positive cells. Images of representative staining were captured using a microscope (BX51; Olympus, Tokyo, Japan).

Immunofluorescent staining and lectin fluorescent staining. The cells were cultured on glass coverslips. Following $48 \mathrm{~h}$ of treatment with TM $(0.5 \mu \mathrm{g} / \mathrm{ml})$ and Cis $(20 \mu \mathrm{M})$, the cells were fixed in $4 \%$ paraformaldehyde or cold acetone for $30 \mathrm{~min}$, followed by blocking with $1 \%$ goat serum for $2 \mathrm{~h}$. Coverslips were incubated with PTX 3 antibody at $4^{\circ} \mathrm{C}$ overnight followed by incubation with TRITC-conjugated goat anti-rabbit IgG (1:50 dilution, \#6926-100; BioVision, Milpitas, CA, USA). For PHA lectin fluorescent staining, the samples were incubated with PHA (\#B-1115; Vector Laboratories) for $1 \mathrm{~h}$. After washing, the samples were incubated with FITC-conjugated streptavidin for $45 \mathrm{~min}$. Following incubation with DAPI for 10 min, coverslips were dropped with an anti-fade solution (Beyotime Biotechnology), and photographed under a fluorescent microscope (BX51; Olympus, Tokyo, Japan).

Reverse transcription-quantitative PCR (RT-qPCR). Total RNA was isolated from the lung cancer cells using TRIzol reagent (Takara, Dalian, China), and prepared for complementary DNA (cDNA) synthesis. RNA was reverse transcribed into cDNA using the Prime Script ${ }^{\mathrm{TM}}$ RT reagent kit (Takara, Tokyo, Japan). The SYBR-Green PCR Master Mix kit (Transgene, Shenzhen, China) was used according to the manufacturer's instructions. The conditions for qPCR were as follows: cycle 1 : $95^{\circ} \mathrm{C}$ for $10 \mathrm{~min}$; cycle $2(\mathrm{x} 40)$ : $95^{\circ} \mathrm{C}$ for $10 \mathrm{sec}$ and $58^{\circ} \mathrm{C}$ for $45 \mathrm{sec}$. Specific primers were designed and prepared (Invitrogen/Thermo Fisher Scientific, Inc.): which included PTX3, 5'-CATCCAGTGAGACCAATGAG-3' (forward) and 5'-GTAGCCGCCAGTTCACCATT-3' (reverse); GAPDH, 5'-GCTGTGTGGCAAAGTCCAA-3' (forward) and 5'-GGTCAGGCTCCTGGAAGATA-3' (reverse). Quantitative PCR reactions were performed with the Applied Biosystems StepOne Real-time PCR system (Life Technologies, Carlsbad, CA, USA). The gene expression was normalized to the GAPDH level as an internal control, and calculated using the $2^{-\Delta \Delta \mathrm{Cq}}$ method (29). Data were presented from 3 independent experiments.

ELISA.Human PTX3 ELISA kit (Boster Biological Technology Co., Ltd., Fremont, CA, USA) was used to measure the PTX3 level in human serum samples and cell culture supernatant according to the manufacturer's instructions. Sample concentrations were calculated from a standard curve generated by dilutions of a known amount of recombinant human PTX3 protein. Each standard or sample was assayed in duplicate. Three internal quality control serum samples or culture were tested in each assay to assess inter-assay precision.

Cell viability assay. Cell viability was assessed by CCK-8 assay. Briefly, the cells were seeded in 96-well plate at a density of 1,000 cells/well and incubated at $37^{\circ} \mathrm{C}$ for 24 to $96 \mathrm{~h}$; the CCK-8 solution, $10 \mu \mathrm{l}$ was added to each well, followed by incubation for $2 \mathrm{~h}$. The absorbance value of each well was measured at $450 \mathrm{~nm}$. Three wells were used in all experiments and repeated at least 3 times.

Wound healing assay. Wound healing assay was performed following the drug treatment. In brief, the cells were cultured in a 6 -well plate reaching at least $80 \%$ confluence. The cells were then incubated at $37^{\circ} \mathrm{C}$ for $0-48 \mathrm{~h}$ in the culture medium containing TM $(0.5 \mu \mathrm{g} / \mathrm{ml})$, Cis $(20 \mu \mathrm{M})$, dePTX3. Cell migration was observed using a light microscope and quantified by the relative wound healing width as the distance of the cells migrated across the injury line at 0 and $48 \mathrm{~h}$.

Transwell migration and invasion assay. For cell migration assay, transwell inserts (Corning Costar, Cambridge, MA, USA) containing polycarbonate filters with $8 \mu \mathrm{m}$ pores were not precoated with Matrigel matrix. For cell invasion assay, the inserts were precoated with Matrigel matrix. 1x10 A549 and SPCA1 cells in $200 \mu \mathrm{l}$ of serum-free RPMI-1640 were added to the upper chamber, and the medium with $10 \%$ FBS was added to the lower chamber. Following $16 \mathrm{~h}$ of incubation, the cells on the lower surface of the filter were fixed, stained and examined under an inverted microscope (Leica Microsystems, Wetzlar, Germany). The number of migrated and invaded cells in 5 random fields (magnification, x100) from triplicate filters was counted, and representative images and statistical analysis were shown.

Colony formation assay. Cells were plated in 6-well plate at 250 cells per well. Following incubation at $37^{\circ} \mathrm{C}$ for 15 days, the cells were washed twice with PBS and stained with Giemsa (BDH Chemicals Ltd., Poole, UK) solution for 5 min. After 3 times of rinsing in sterile water, the number of colonies containing $\geq 50$ cells was counted under an inverted microsrope. 
Deglycosylation treatment. The A549 and SPCA1 cells were used to determine the role of PTX3 glycosylation in lung cancer growth. PTX3 was deglycosylated by mixing rhPTX3 (100 ng/ml) with PNGase F $(500 \mathrm{U} / \mathrm{ml})$ for $2 \mathrm{~h}$ at $37^{\circ} \mathrm{C}$. Subsequently, the cells were treated with dePTX3 and various concentrations of TM as indicated in Fig. 2.

Plasmid construction and site-directed mutagenesis. A plasmid pcDNA3.1-PTX3 containing the human full-length PTX3 cDNA (GenBank accession no. NM_002852.3) was used to produce the PTX3 N-glycan site mutant. The mutated plasmid (mPTX3) was constructed by replacement of asparagine 220 (Asn-220) to glutamine according to the manufacturer's instructions (GenePharma, Shanghai, China). The mutation was further confirmed by DNA sequencing. The cancer cells were transfected with mPTX3 by using Lipofectamine 2000 (Invitrogen/Thermo Fisher Scientific, Inc.).

Western blot analysis. The cells were washed with PBS ( $\mathrm{pH} 7.4)$, and incubated with $2 \mathrm{x}$ concentrated electrophoresis sample buffer $(125 \mathrm{mM}$ Tris- $\mathrm{HCl}, \mathrm{pH} 6.8,5 \%$ glycerol, $2 \% \mathrm{SDS}, 1 \% \beta$-mercaptoethanol) for $30 \mathrm{~min}$ on ice. Protein concentration was determined with Coomassie protein assay reagent using bovine serum albumin as a standard. Total protein from the whole cell lysates was separated by $12 \%$ SDS-PAGE gel, and transferred electrophoretically onto PVDF membranes, incubated with TBST $(50 \mathrm{mM}$ Tris $\mathrm{HCl}, \mathrm{pH} 7.5,0.15 \mathrm{M} \mathrm{NaCl}, 0.1 \%$ Tween-20) containing $5 \%$ fat-free dry milk for $2 \mathrm{~h}$, followed by overnight incubation with the appropriate primary antibodies at the dilutions recommended by the suppliers at $4^{\circ} \mathrm{C}$. Following incubation with an HRP-conjugated appropriate secondary antibody, the enhanced electrochemical luminescence (ECL) detection system (Bio-Rad Laboratories, Hercules, CA, USA) was used to visualize immunoreactive bands. The primary antibodies to PTX3 (rabbit antibody, 1:200), MMP-9 (rabbit antibody, 1:200), AKT, p-AKT (T308), p65, p-p65, Bcl2, Bax, cleaved PARP, IKK, p-IKK and GAPDH (rabbit antibodies, 1:1,000) were used. The amount of each protein was determined by the intensity of the band. To verify equal protein loading, the GAPDH level in each lane was examined with the anti-GAPDH antibody. Bands were semi-quantified with Image software.

Analysis of cell apoptosis by flow cytometry. The A549 and SPCA1 cells were cultivated in a 6 -well plate at a concentration of $2 \times 10^{5}$ cells/well and then incubated at $37^{\circ} \mathrm{C}$ with $\mathrm{TM}$ $(0.5 \mu \mathrm{g} / \mathrm{ml})$ or Cis $(20 \mu \mathrm{M})$ alone or in combination for $24 \mathrm{~h}$. Untreated cells were used as a negative control. The cells were washed with PBS twice and followed by trypsinization. The cells were stained with Annexin V-FITC/propidium iodide (PI) apoptosis detection kit (Nanjing KeyGen Biotech Co., Ltd., Nanjing, China) as per the manufacturer's recommendations. The fluorescence intensity of the samples was determined by flow cytometry. The number of apoptotic cells in each treatment was detected by flow cytometric analysis (BD Acuri ${ }^{\mathrm{TM}}$ C6; BD Biosciences, San Jose, CA, USA). The data were presented as the total number of apoptotic cells in each treatment. The whole experiment was carried out in triplicate and the error bars were calculated from the independently repeated experiments.
Statistical analysis. The experiments were repeated at least 3 times, and the results were expressed as the means \pm SEM. Data were analyzed using the Student's t-test and an analysis of variance (one-way ANOVA) test followed by a Tukey's post hoc test were applied to determine the significant differences between groups. A P-value $<0.05$ was considered as statistically significant. The statistical analysis was performed using GraphPad-Prism 6 software (GraphPad-Prism Software Inc., San Diego, CA, USA).

\section{Results}

PTX3 expression in human lung cancer samples and cell lines. PTX3 expression was detected in human lung cancer tissues and serum. Immunohistochemical staining of PTX3 protein revealed a significant difference between the lung cancer tissues and normal tissues. Positive PTX3 staining was observed in 24 of 34 (70.59\%) lung cancer tissues compared with the normal tissues in 8 out of $42(19.04 \%)$. Represented images were shown in Fig. 1A. PTX3 level detected by ELISA in the serum of patients with lung cancer $(12.01 \pm 0.85)$ was higher than that in the normal controls $(5.57 \pm 0.51)$ (Fig. 1B). PTX3 in the supernatant (suPTX3) was also detected by ELISA in 3 types of lung cancer cells (A549, SPCA1 and H1299) (Fig. 1C). Comparatively, the expression of PTX3 was found in A549, SPCA1 and H1299 cells examined by immunofluorescent staining, RT-qPCR and western blot analysis (Fig. 1D-F). These results suggest that the PTX3 expression level is high in human lung cancer tissues, and PTX3 can be generated by lung cancer cells.

dePTX3 suppresses the growth and migration of human lung cancer cells. The A549 and SPCA1 cells were used to determine the role of PTX3 glycosylation in lung cancer growth. The glycosylated rhPTX3 was deglycosylated by incubation with PNGase F (500 U/ml), an enzyme that cleaves Asn-linked high mannose, as well as hybrid and complex oligosaccharides for $2 \mathrm{~h}$ at $37^{\circ} \mathrm{C}$. Lung cancer cells were treated with $\mathrm{rhPTX} 3(100 \mathrm{ng} / \mathrm{ml})$ or dePTX3, respectively. The results of CCK-8 assay revealed that cell viability was significantly inhibited following treatment with dePTX3, while increased in response to rhPTX3 treatment in both A549 and SPCA1 cells. Differences in viability between the rhPTX3 - and dePTX3-treated cells were more significant after 48 and $72 \mathrm{~h}$ incubation (Fig. 2A). We found that treatment with 0.5 or $1 \mu \mathrm{g} / \mathrm{ml} \mathrm{TM}$ significantly inhibited the viability of A549 and SPCA1 cells in comparison with the untreated control (Fig. 2B). PHA is a lectin which can recognize and bind with the $\mathrm{N}$-glycans of glycoproteins. We further investigated the binding of FITC-conjugated PHA to evaluate changes in $\mathrm{N}$-deglycosylation in response to TM. The A549 and SPCA1 cells treated with TM exhibited decreased PHA-L binding compared to the untreated cells, as well as a lower level of N-glycan PTX3 (Fig. 2C). A 12\% SDS-PAGE gel stained with $\mathrm{CBB}$ revealed that both the untreated cells and cells treated with TM or PNGase F enzyme had comparable loading of proteins in each lane, and the lectin blot showed that the untreated cells had stronger $\mathrm{N}$-glycan bands than the cells treated with TM $(0.5 \mu \mathrm{g} / \mathrm{ml})$ for $48 \mathrm{~h}$ and PNGase F enzyme $(500 \mathrm{U} / \mathrm{ml})$ for $2 \mathrm{~h}$ (Fig. 2D). Treatment of the lung cancer cells with TM or 
A
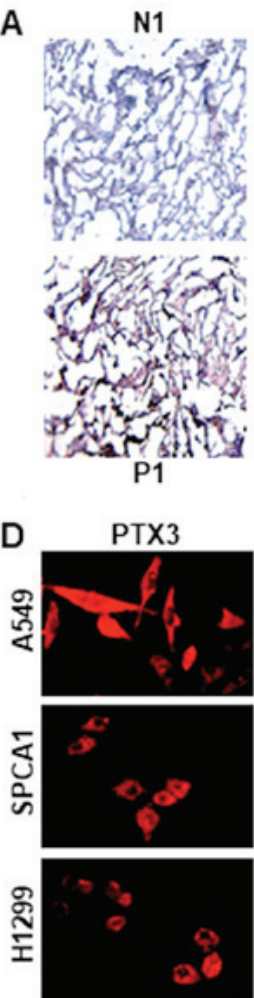

N2

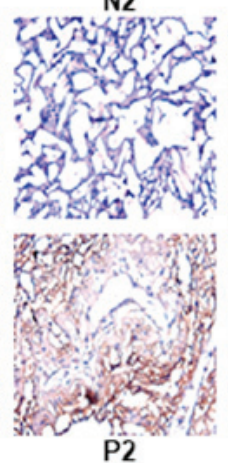

P2
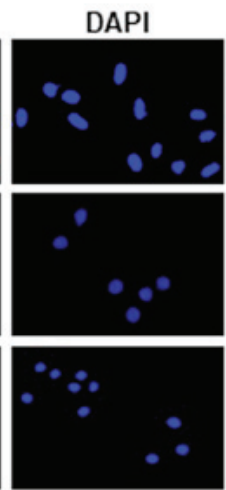

N3
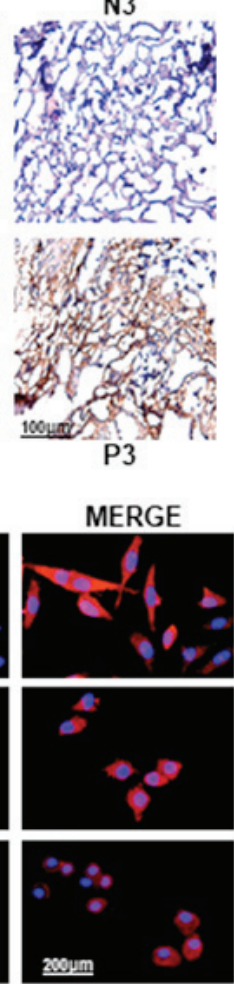

B

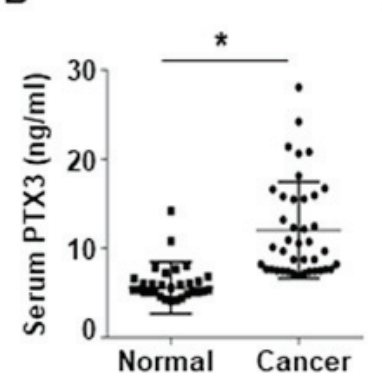

E

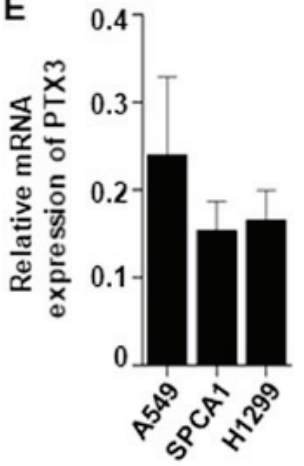

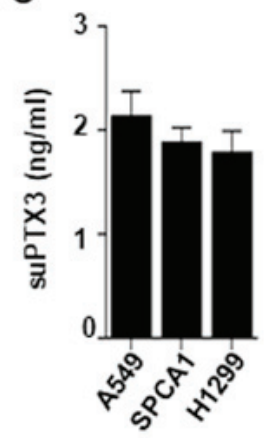

$\mathbf{F}$

C

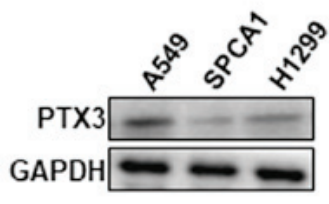

Figure 1. PTX3 expression in human lung cancer samples and cell lines. (A) Immunohistochemical staining of PTX3 in paired human lung cancer tissue (P1, P2, P3) and normal lung tissue (N1, N2, N3) of the same patient (magnification, x10). (B) PTX3 level in serum from lung cancer patients and normal healthy individuals by ELISA; *P<0.05. (C) PTX3 level in the supernatant collected from A549, SPCA1 and H1299 cells was examined by ELISA. (D) Immunofluorescent staining of PTX3 protein (red color) in A549, SPCA1 and H1299 lung cancer cells. DAPI (blue color) was used to stain the nuclei. (E) mRNA expression level of PTX3 detected by qPCR in A549, SPCA1 and H1299 cells. (F) PTX3 expression level in A549, SPCA1 and H1299 cells detected by western blot analysis. GAPDH was used as an internal control.

rhPTX3 + PNGase F incubation resulted in a decrease in the apparent molecular mass of PTX3 approximately $4 \mathrm{kDa}$, from 45 to $41 \mathrm{kDa}$ (Fig. 2E) (lane 1, glycosylated PTX3; lane 2, dePTX3 by TM; lane 3, dePTX3 by PNGase F). Moreover, the results of wound healing and migration assays indicated that rhPTX3 treatment significantly increased the migratory ability of A549 and SPCA1 cells compared with the cells treated with dePTX3 or TM $(0.5 \mu \mathrm{g} / \mathrm{ml})$ after $48 \mathrm{~h}$ (Fig. 2F and G). These results suggest that PTX3 deglycosylation inhibits lung cancer cell growth and migration.

PTX3 deglycosylation enhances the sensitivity of lung cancer cells to cisplatin treatment. The results of ELISA revealed that suPTX3 level was significantly higher in the supernatant medium of Cis-treated A549 and SPCA1 cells than that in the control (Fig. 3A). The immunofluorescent staining of PTX3 expression confirmed that the Cis-treated A549 and SPCA1 cells exhibited an increased expression of PTX3 compared to the untreated cells. DAPI was used to stain the nuclei, as shown in Fig. 3B. We further examined the effects of PTX3 deglycosylation on the sensitivity of lung cancer cells to Cis. Lung cancer cells were treated with Cis alone or in combination with dePTX3. Cell viability was assessed by CCK-8 assay, which revealed that Cis suppressed the viability of A549 and SPCA1 cells. However, following combined treatment with dePTX3 and Cis, dePTX3 was found to significantly enhance the suppressive effects of $\mathrm{Cis}$ on the viability of both cell lines, as shown in Fig. 3C. Western blot analysis of PCNA expression confirmed the increased anti-proliferative effects of Cis following combined treatment with dePTX3 in both A549 and SPCA1 (Fig. 3D). We also examined cell signaling pathway-related proteins, specifically AKT phosphorylation following treatment with Cis or combined treatment with dePTX3. Combined treatment with Cis and dePTX3 for $48 \mathrm{~h}$ suppressed AKT phosphorylation compared to Cis treatment alone, as shown in Fig. 3D. These results suggest that dePTX3 enhances the sensitivity of lung cancer cells to Cis. We also sought to determine whether mPTX3 enhanced the antitumor effects of Cis through an AKT-dependent pathway. First, we examined the efficiency of the mutated PTX3 by western blot analysis, which indicated a successful PTX3 mutation (Fig. 3E). As expected, combined treatment with dePTX3 and Cis decreased PCNA expression and consistent results were observed following the use of Cis and mPTX3 (Fig. 3F), and mPTX3 enhanced the antitumor effects of Cis on the A549 and SPCA1 cells. This finding led us to examine the role of PTX3 glycosylation in lung cancer progression.

TM enhances the suppressive effects of cisplatin in lung cancer cells. We used TM to enhance Cis drug sensitivity, demonstrating the suppression of lung cancer growth and metastasis. The results of CCK-8 assay revealed that combined treatment with TM and Cis significantly suppressed the viability of both A549 and SPCA1 cells in a time-dependent manner. Combined treatment inhibited cell growth 2.0 fold in A549 cells and 2.5-fold in SPCA1 cells compared with no 

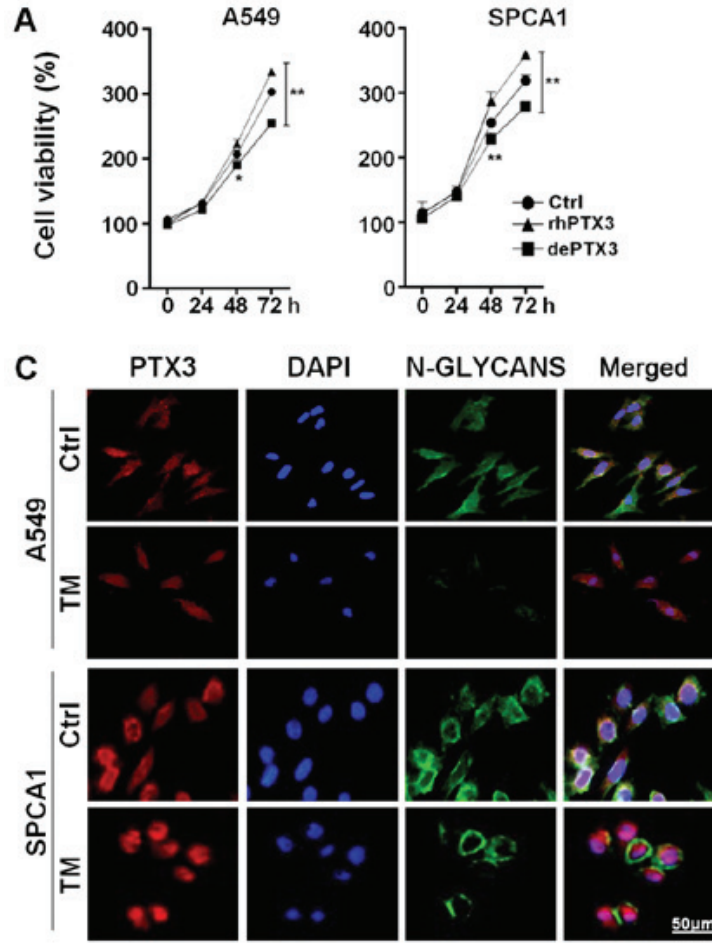

$\mathbf{F}$

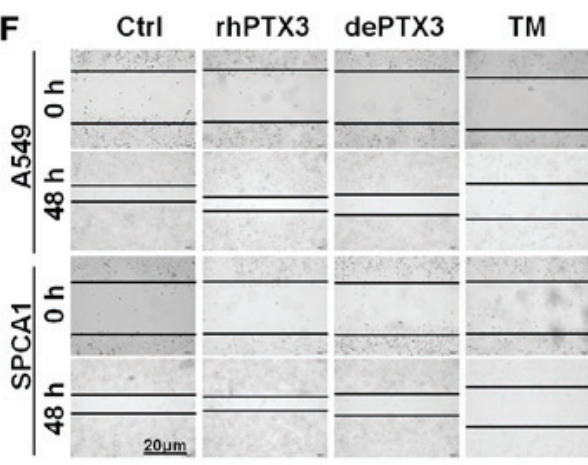

G

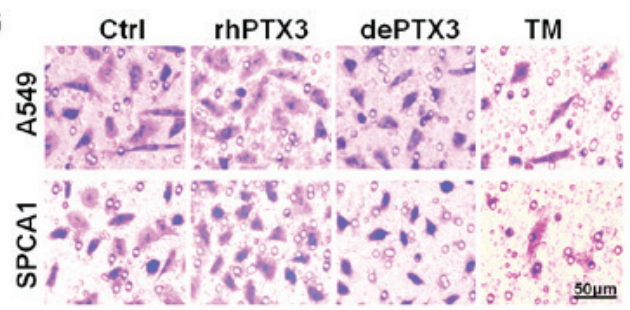

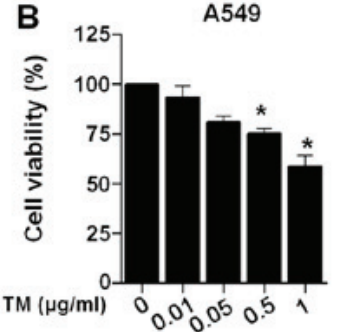

D
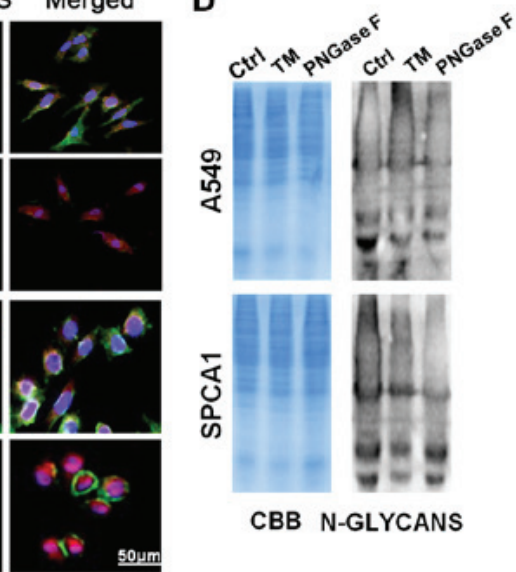

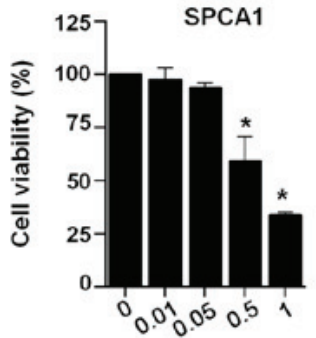

E
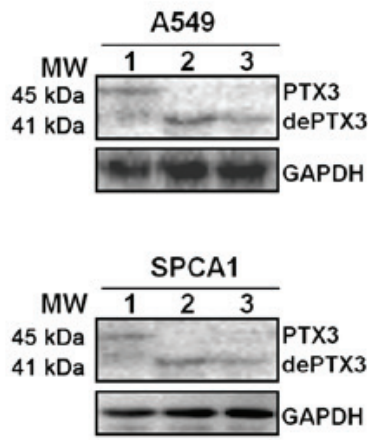
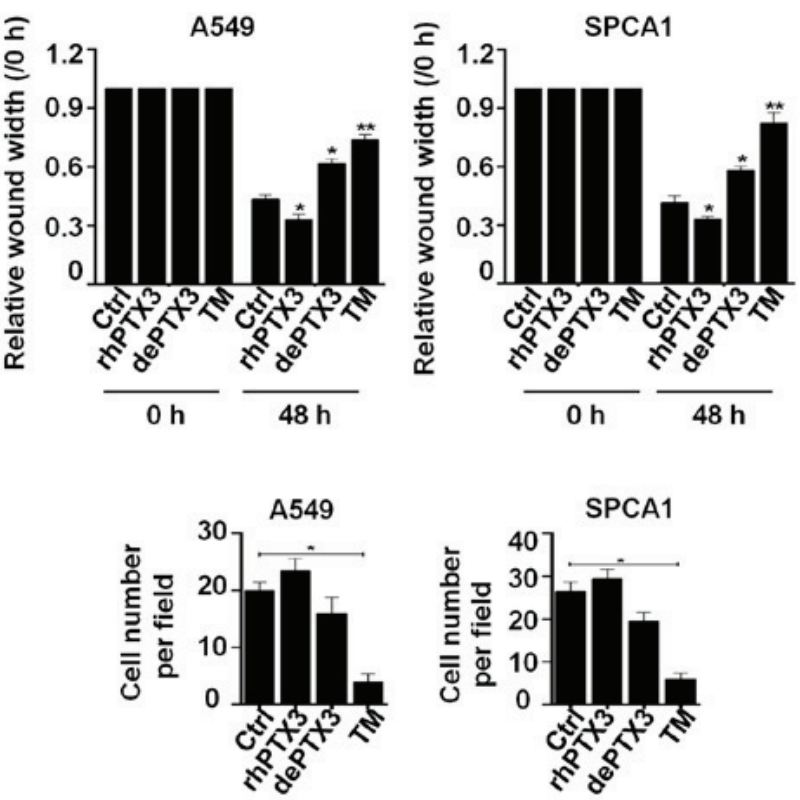

Figure 2. dePTX3 suppresses the growth and migration of human lung cancer cells. (A) CCK-8 assay was used to analyze the viability of A549 and SPCA1 cells. Cells were treated with or without rhPTX3 (100 ng/ml) or dePTX3 (rhPTX3; $100 \mathrm{ng} / \mathrm{ml}+\mathrm{PNGase} \mathrm{F}$; $500 \mathrm{U} / \mathrm{ml})$ for 0-72 h. Data were presented as a percentage of viable cells. (B) Lung cancer cells treated with TM $(0.01,0.05,0.5 \mathrm{and} 1 \mu \mathrm{g} / \mathrm{ml})$ for $48 \mathrm{~h}$. (C) Immunofluorescent staining of PTX3 (red color) and N-glycan levels (green color) in A549 and SPCA1 cells analyzed following treatment with TM (0.5 $\mu \mathrm{g} / \mathrm{ml})$ for $48 \mathrm{~h}$. (D) SDS-PAGE gel (12\%) stained with $\mathrm{CBB}$ and lectinblot against PHA to analyze N-glycans in lung cancer cells following treatment with TM for $48 \mathrm{~h}$ and PNGase F (500 U/ml) for $2 \mathrm{~h}$ of incubation. (E) Western blot analysis of dePTX3 in A549 and SPCA1 cells following treatment with TM or rhPTX3 + PNGase F. The lanes are labeled as follows: lane 1, glycosylated PTX3; lane 2, deglycosylated PTX3 by TM; lane 3, deglycosylated PTX3 by PNGase F. (F) Representative images of wound healing of A549 and SPCA1 cells analyzed after treatment with rhPTX3, dePTX3 and TM $(0.5 \mu \mathrm{g} / \mathrm{ml})$, followed by measurement of relative wound width (48 h average wound width divided by $0 \mathrm{~h}$ wound width). (G) Microscopic images and graphs of transwell migration assay of A549 and SPCA1 cells following treatment with rhPTX3, dePTX3 and TM. Bar graph values represent the means \pm SEM of 3 independent experiments. ${ }^{*} \mathrm{P}<0.05$ and ${ }^{* *} \mathrm{P}<0.01$.

treatment cells (Fig. 4A). The results of colony formation assay were consistent with CCK-8 assay, demonstrated a significant decrease in cell viability in both cell lines following combined treatment. Colony formation was reduced by 25 and $50 \%$ in A549 cells and by 45 and $70 \%$ in SPCA1 cells treated with Cis alone or TM + Cis (Fig. $4 \mathrm{~B}$ ). These results suggest that $\mathrm{TM}$ potently enhanced the anti-proliferative effects of $\mathrm{Cis}$ on lung cancer cells. Wound healing assay revealed that combined treatment significantly decreased cell migration compared to no treatment or individual TM or Cis treatment after $48 \mathrm{~h}$ (Fig. 4C). These results were consistent with that of transwell migration and Matrigel invasion assay of A549 and SPCA1 cells, which indicated that combined treatment inhibited the invasion of the A549 and SPCA1 cells more 
A

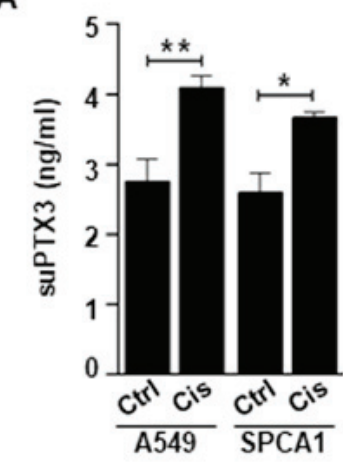

B

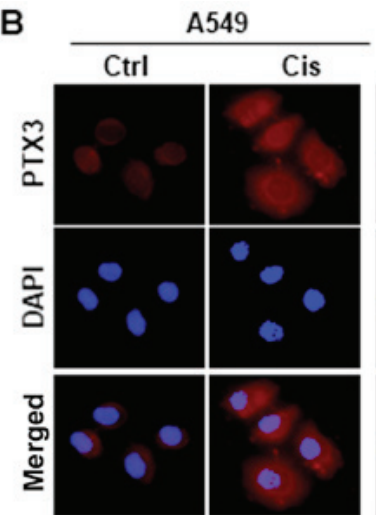

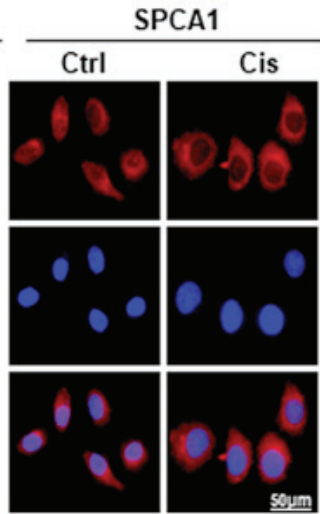

C

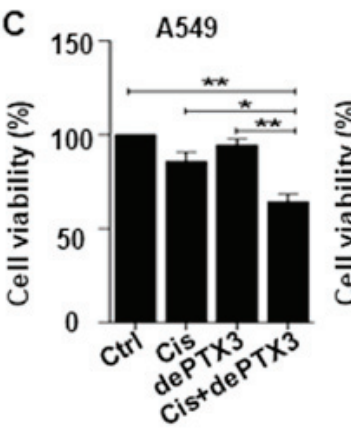

E

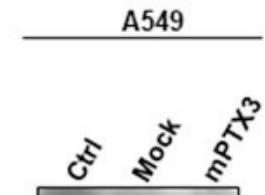

PTX3

GAPDH
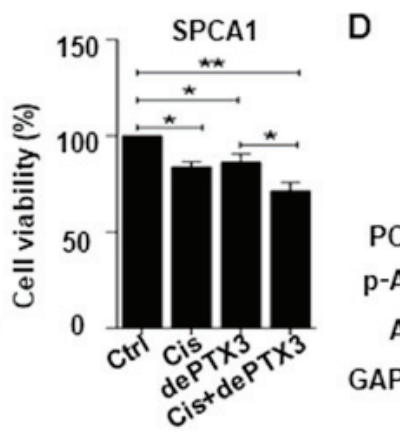

D
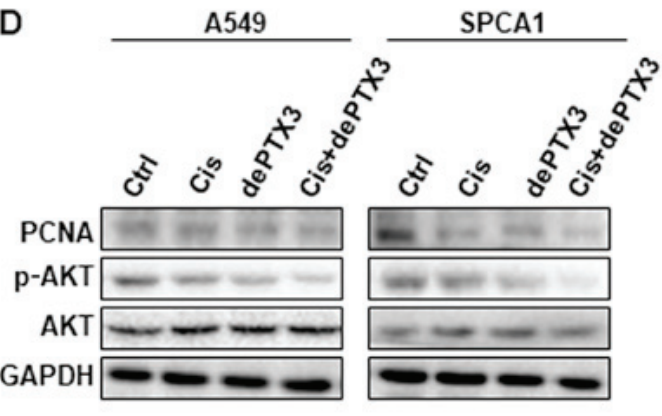

$\mathbf{F}$

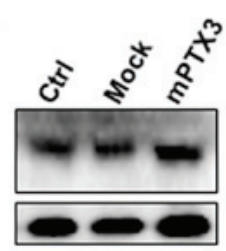

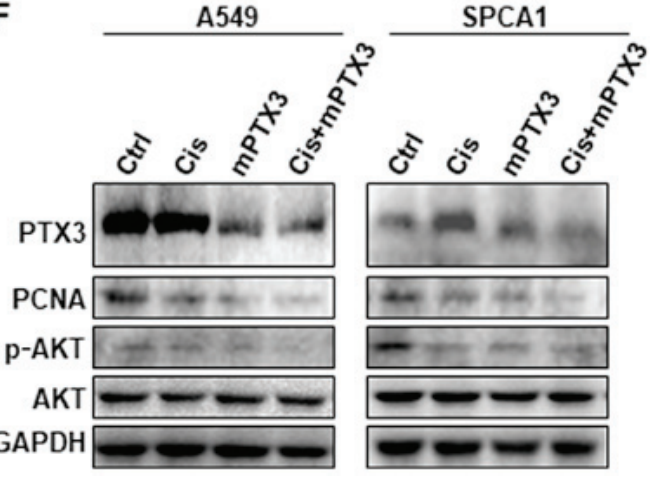

Figure 3. PTX3 deglycosylation enhances the sensitivity of lung cancer cells to Cisplatin treatment. (A) suPTX3 level was detected by ELISA in the supernatant of A549 and SPCA1 cells following treatment with Cis $(20 \mu \mathrm{M})$ for $48 \mathrm{~h}$. (B) Immunofluorescent staining of PTX3 (red color) in A549 and SPCA1 cells following treatment with Cis for $48 \mathrm{~h}$. DAPI (blue color) was used to stain the nuclei. (C) Bar graph of A549 and SPCA1 cell viability analyzed following treatment with Cis and deglycosylated PTX3 (dePTX3). Each bar represents the average of 3 independent experiments. Data are expressed as a percentage of viable cells. (D) Western blot analysis of PCNA and AKT phosphorylation following treatment with Cis or dePTX3, and combined treatment for $48 \mathrm{~h}$. (E) Western blot analysis for PTX3 expression in the cell lysate from control, mock and mutated PTX3 (mPTX3) in A549 and SPCA1 cells. (F) Western blot analysis of Cis, mPTX3 or Cis combined with mPTX3 and combined treatment for $48 \mathrm{~h}$. The level of PCNA expression and AKT phosphorylation were examined by western blot analysis. GAPDH was used as an internal control. ${ }^{*} \mathrm{P}<0.05$ and ${ }^{* *} \mathrm{P}<0.01$.

significantly than no treatment or treatment with TM or Cis alone (Fig. 4D and E). Western blot analysis of the proliferative marker, PCNA, also confirmed the anti-proliferative activity in the A549 and SPCA1 cells following combined treatment, with a decrease in PCNA expression compared to the expression in the individually treated or untreated cells. Furthermore, cells treated with the combined treatment expressed lower level of MMP-9 than the untreated cells (Fig. 4F). The data indicate that TM enhances the chemosensitivity of lung cancer cells by inhibiting proliferation and metastasis.

TM the sensitivity of lung cancer cells to cisplatin-induced apoptosis through deactivating $A K T / N F-\kappa B$ signaling pathway. We probed downstream signaling pathways of PTX3 using the inhibitors, including GDC0941 (an inhibitor of AKT phosphorylation), MEK162 (an inhibitor of MEK1/2) and IKK-16 (an inhibitor of NF- $\mathrm{B}$ phosphorylation). The results of CCK-8 assay revealed that treatment with rhPTX3 and the inhibitors targeting $\mathrm{AKT} / \mathrm{NF}-\kappa \mathrm{B}$ pathway led to an enhanced inhibition of the viability and proliferation of A549 and SPCA1 cells compared to the cells treated with rhPTX3 alone (Fig. 5A). The cells were treated with IKK-16 to determine whether NF- $\mathrm{NB}$ was associated with the PTX3-mediated regulation of $\mathrm{Bcl} 2$. The results indicated that treatment with IKK-16 inhibited the PTX3-mediated upregulation of $\mathrm{Bcl} 2$ expression in both A549 and SPCA1 cells (Fig. 5B). Taken together, the evidence suggest that lung cancer cell survival is positively regulated by PTX3, likely through $\mathrm{AKT} / \mathrm{NF}-\kappa \mathrm{B}$ pathway and $\mathrm{Bcl} 2$ upregulation. We then sought to determine whether TM enhanced the anticancer effects of Cis through 
A

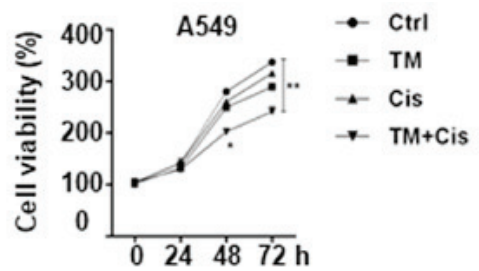

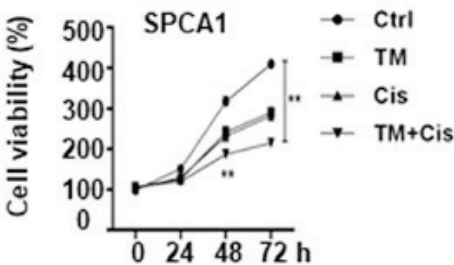

$\mathbf{B}$

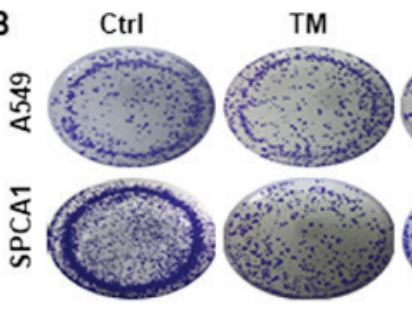

C
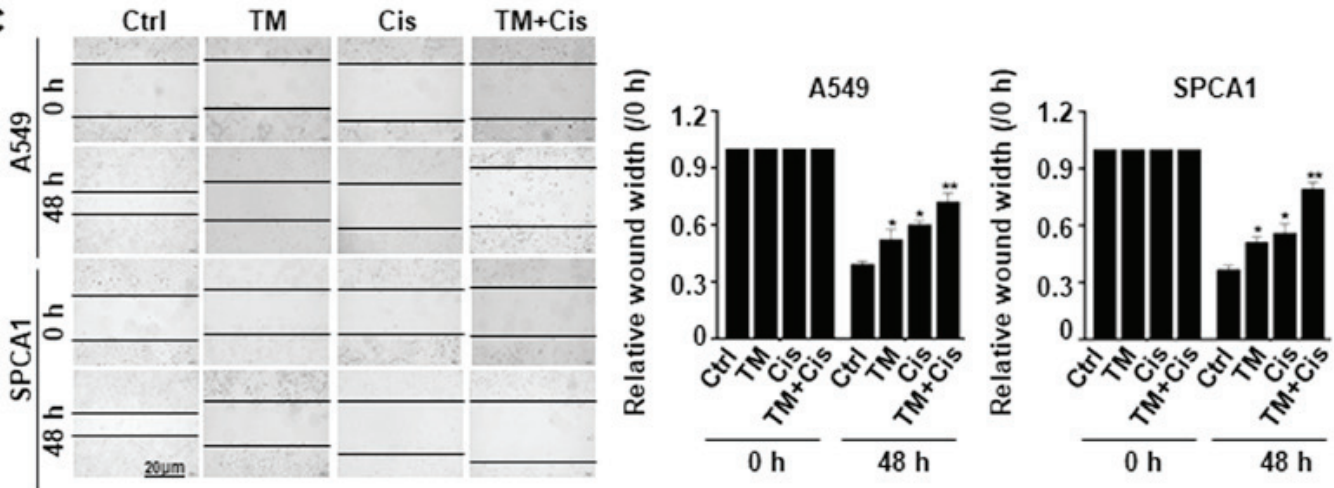

D

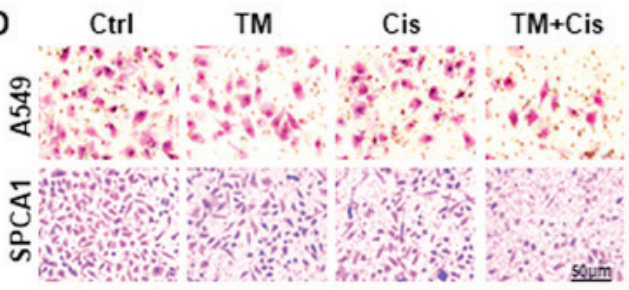

E

TM

Cis

$\mathrm{TM}+\mathrm{C}$ is

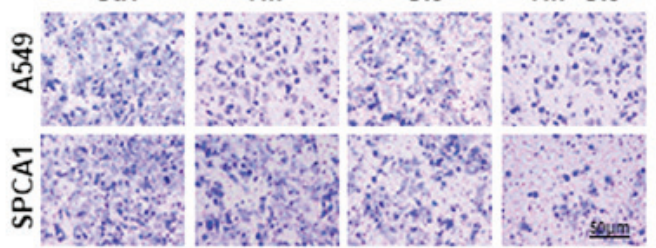

$\mathbf{F}$

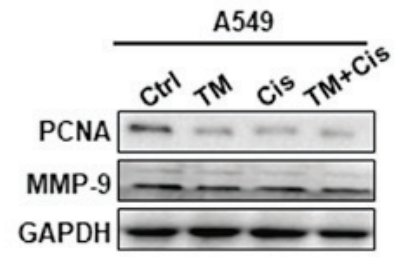

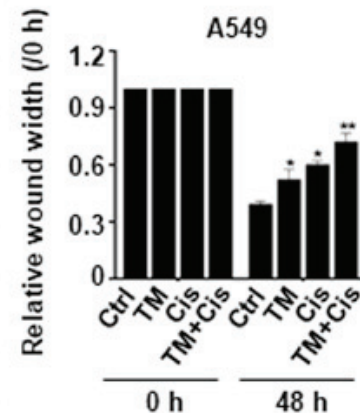
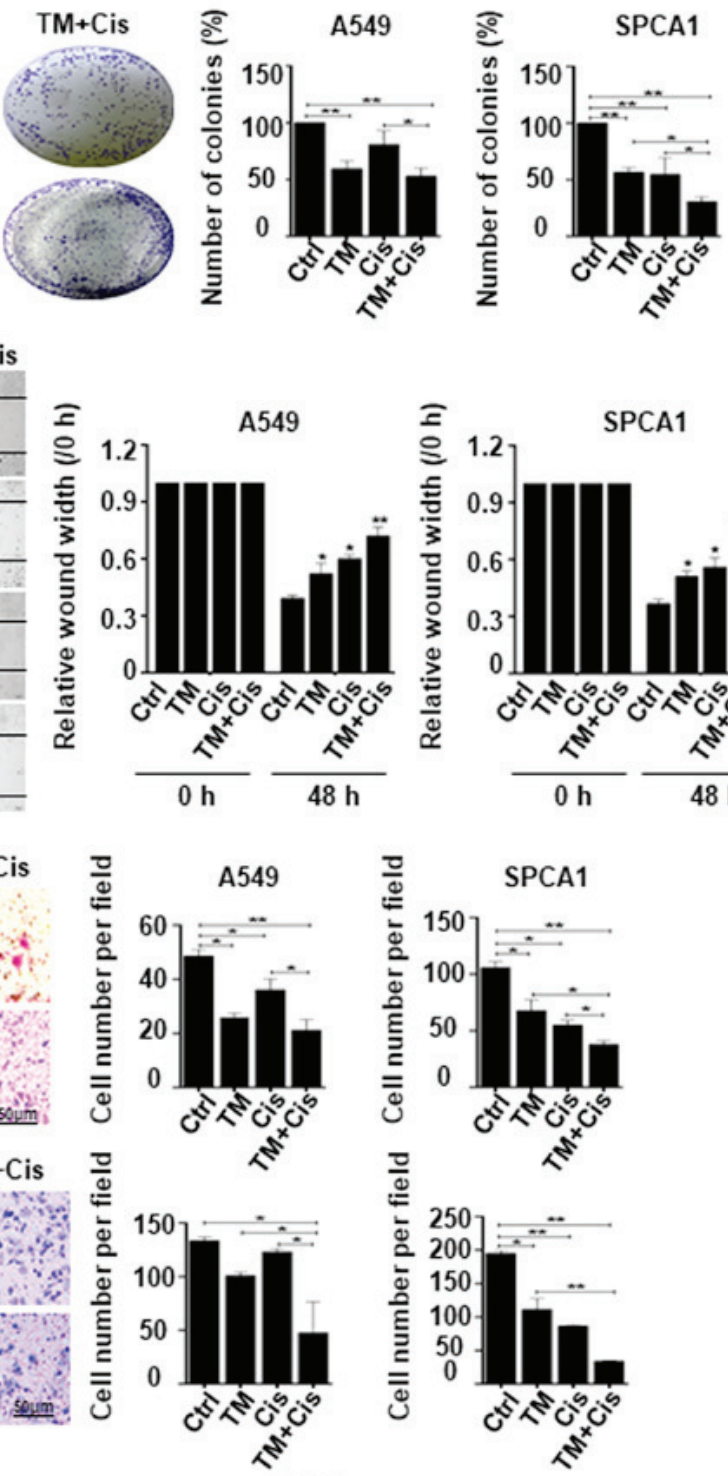

SPCA1

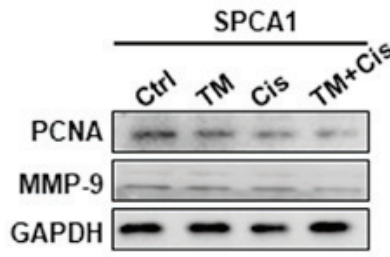

Figure 4. TM enhances the suppressive effects of cisplatin in lung cancer cells. (A) CCK-8 assay was used to examine the viability of A549 and SPCA1 cells treated with TM, Cis or in combination for 0-72 h. Data were expressed as a percentage of viable cells. (B) Representative images of A549 and SPCA1 cell colonies following treatment with TM, Cis. (C) Images representation of wound healing of A549 and SPCA1 cells analyzed following treatment with TM or Cis alone or in combination, graphs were the measurement of relative wound width ( $48 \mathrm{~h}$ average wound width divided by $0 \mathrm{~h}$ wound width). (D) Images and graphs of transwell assay of A549 and SPCA1 cells following treatment with TM, Cis alone or in combination. (E) Invasion ability of A549 and SPCA1 cells following treatment with TM, Cis alone or in combination for $15 \mathrm{~h}$. Bar graph values represented the number of invaded cells from ten different field. (F) Western blot analysis of PCNA and MMP-9 expression following treatment with TM, Cis alone or in combination. GAPDH was used as an internal control. Data was shown as the mean values \pm SEM. ${ }^{*} \mathrm{P}<0.05$ and ${ }^{* *} \mathrm{P}<0.01$.

AKT/NF- $\kappa$ B-dependent pathway. Western blot analysis of cytoplasmic protein extracts revealed that combined treatment with TM and Cis decreased AKT and IKK phosphorylation more significantly than TM or Cis drug treatment alone. 
A

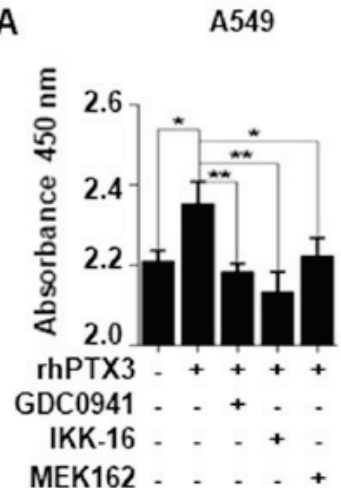

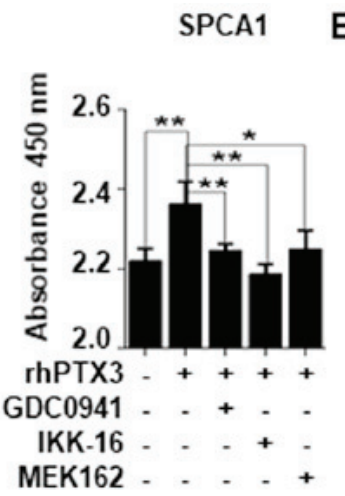

B
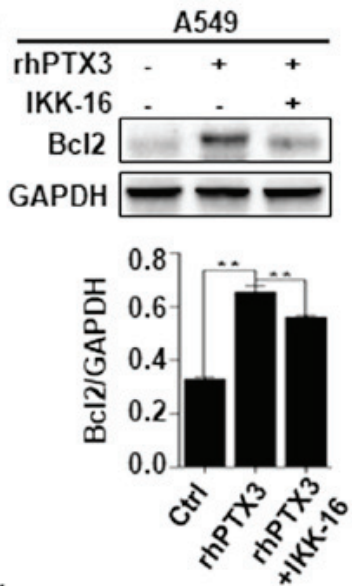

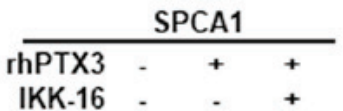

$\mathrm{Bcl} 2+$

GAPDH

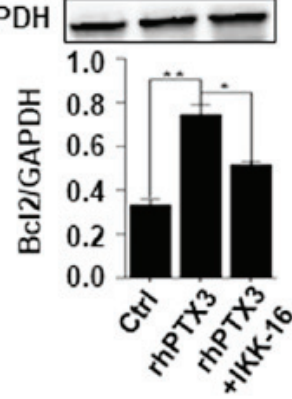

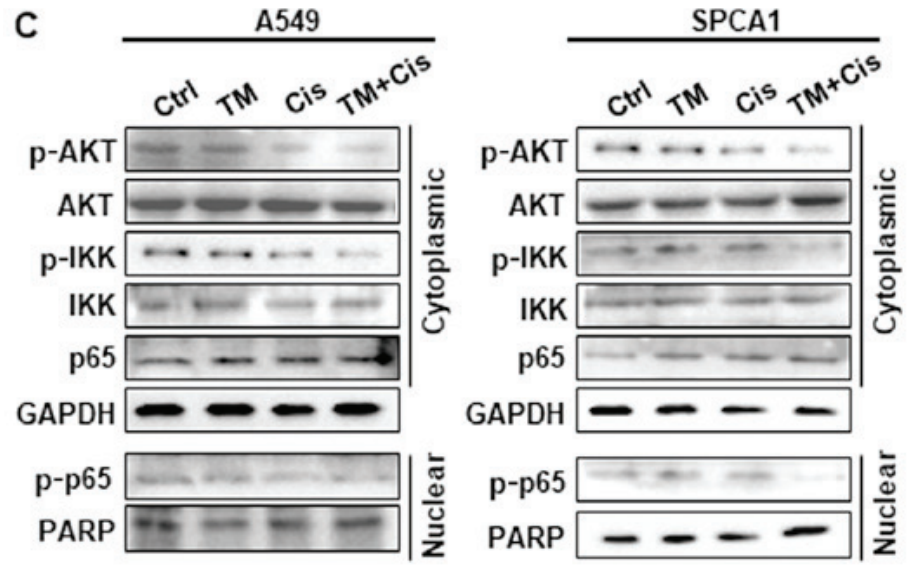
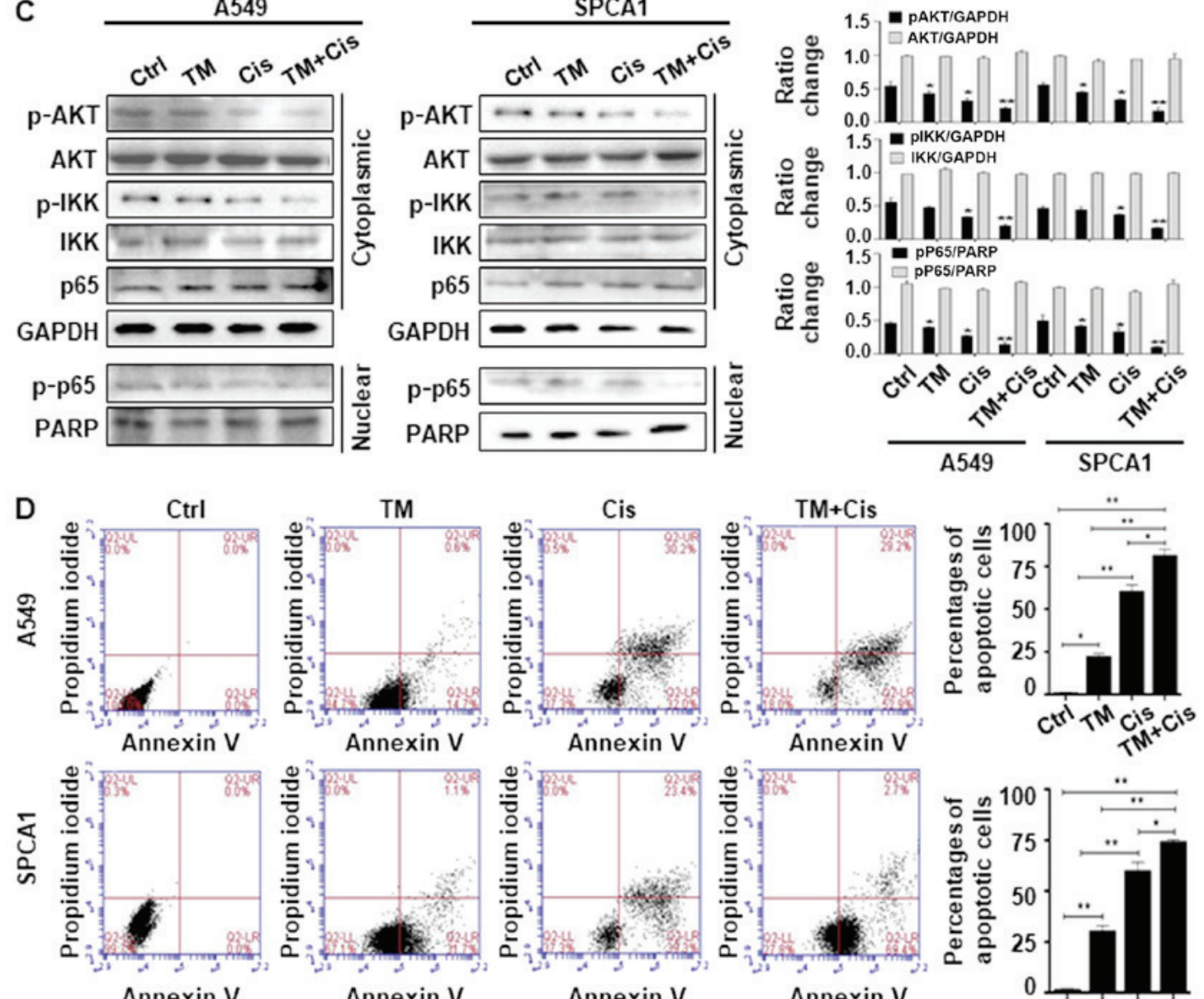

Annexin V

Annexin V

E

A549

SPCA1
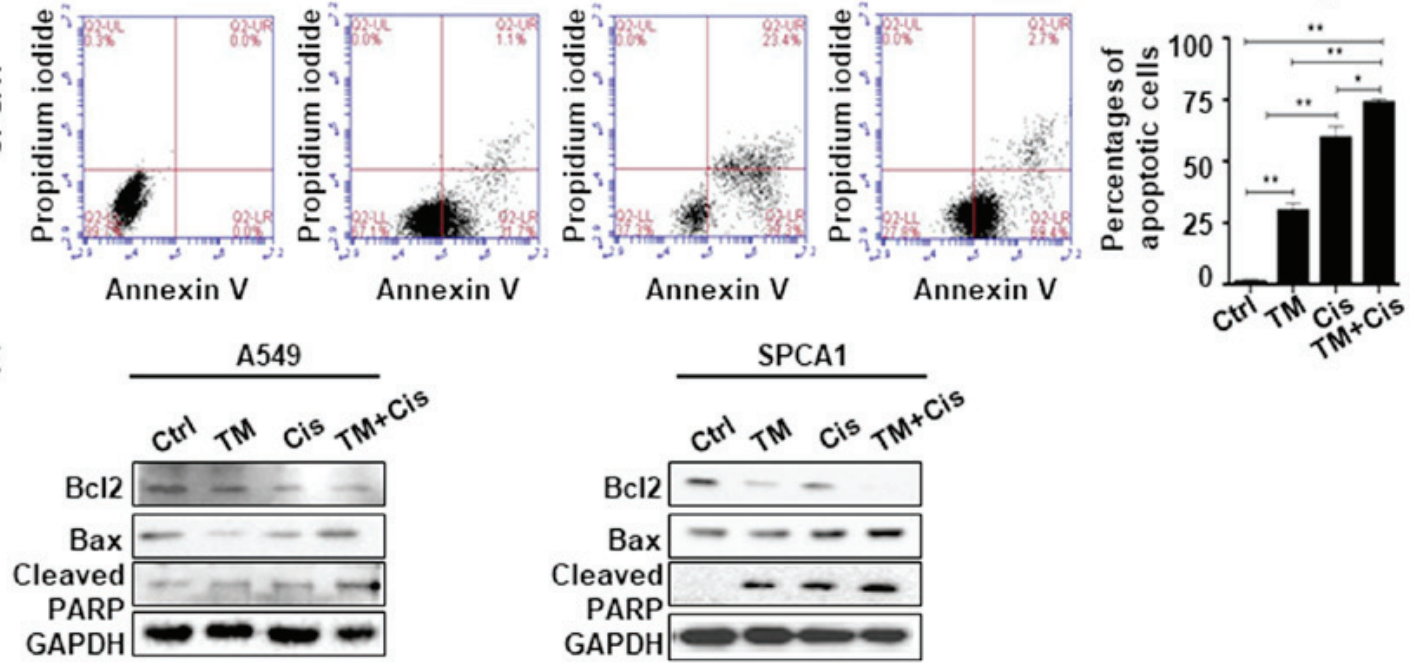

Figure 5. TM increases the sensitivity of lung cancer cells to cisplatin-induced apoptosis through deactivating AKT/NF- $\mathrm{BB}$ signaling pathway. (A) CCK-8 assay used to analyze the viability of A549 and SPCA1 cells treated with GDC0941 (4 $\mu \mathrm{M})$, IKK-16 $(10 \mu \mathrm{M})$, MEK162 $(20 \mu \mathrm{M})$ or rhPTX3 (100 ng/ml) for $48 \mathrm{~h}$. (B) Western blot analysis of Bcl2 expression in A549 and SPCA1 cells, incubated with rhPTX3 (100 ng/ml) with or without NF-kB inhibitor IKK-16 $(10 \mu \mathrm{M})$. (C) A549 and SPCA1 cells were treated with TM $(0.5 \mu \mathrm{g} / \mathrm{ml})+$ Cis $(20 \mu \mathrm{M})$ together or in combination. Western blot analysis of AKT, IKK, p65 phosphorylation in cytoplasmic and nuclear extracts of A549 and SPCA1 cells treated with TM, Cis or in combination. PARP was used as an internal control. (D) A549 and SPCA1 cells were double-stained with Annexin V-FITC/PI and analyzed by flow cytometry after $24 \mathrm{~h}$ of treatment with TM $(0.5 \mu \mathrm{g} / \mathrm{ml}), \mathrm{Cis}$ $(20 \mu \mathrm{M})$ or combined treatment. The histogram showed the average percentage of total apoptotic cells in both A549 and SPCA1 cells. (E) Bcl2, Bax and cleaved PARP expression detected by western blot analysis following treatment with TM, Cis or in combination for $48 \mathrm{~h}$. GAPDH was used as an internal control. Data represented the mean values $\pm \mathrm{SEM}$. ${ }^{*} \mathrm{P}<0.05$ and ${ }^{* *} \mathrm{P}<0.01$ 
Likewise, in nuclear protein extracts, the phosphorylation of p-p65 in the A549 and SPCA1 cells was decreased following treatment (Fig. 5C). An Annexin V FITC/PI apoptosis detection kit was used. The A549 and SPCA1 cells were treated with TM, Cis or in combination for $24 \mathrm{~h}$, and the results of flow cytometry revealed that the percentage of total apoptotic cells was increased significantly than treatment with TM or Cis alone (Fig. 5D). Treatment with TM alone led to an average of 20.3 and $30.5 \%$ total apoptotic A549 and SPCA1 cells, respectively; Cis treatment alone led to an average of 58.4 and 59.2\% total apoptotic A549 and SPCA1 cells, respectively; combined treatment with TM and Cis significantly increased the percentage of apoptotic A549 and SPCA1 cells. The total apoptotic A549 and SPCA1 cells were 80.3 and $73.2 \%$, respectively. These findings confirm that apoptosis is the predominant pattern of cell death induced by combined treatment. We also found that combined treatment with TM and Cis significantly increased the expression level of apoptotic markers, including Bax and cleaved PARP, and simultaneously decreased the expression of $\mathrm{Bcl} 2$, compared with treatment with TM or Cis alone in both A549 and SPCA1 cells (Fig. 5E). These results suggest that the deglycosylation of PTX3 by TM in lung cancer cells treated with Cis inhibits the activation of $\mathrm{AKT} / \mathrm{NF}-\kappa \mathrm{B}$ signaling pathway, promoting the apoptosis of lung cancer cells.

\section{Discussion}

PTX3 is a potential marker of inflammation to detect lung cancer. Recent studies have indicated a significant association between serum PTX3 and cancer malignancy. A proteomics-based study provided evidence that elevated level of PTX3 in lung cancer patients as compared to healthy control by ELISA (30). The increased PTX3 was also found in the serum of liposarcoma, pancreatic and breast cancer $(13,16,31)$. Locatelli et al reported that PTX3 in glioma was significantly correlated with tumor grade and severity assessed by immunohistochemical staining (12). In the current study, the elevated PTX3 level was detected in both human lung cancer serum and tissue by ELISA and immunohistochemical staining. The consistent alterations of PTX3 in serum and tissue of the cancer patients indicated that serum PTX3 could represent the tissue pathogenesis. Moreover, tumorigenesis has been considered as a chronic inflammatory process, and the early release of inflammatory protein PTX3 may be predisposed to the development of cancer. Therefore, the detection of serum PTX3 can be applied as an early marker for cancer diagnosis. Based on the facts in other labs and our results that PTX level is linked to the growth, migration and invasion capability, the inhibition of PTX3 may be a treatment target for lung cancer.

Glycans alter protein structure and conformation and as a result, modulate the functional activities of the glycoprotein (32). Changes in cellular glycosylation have recently been acknowledged as a key component of cancer progression. Alterations in the glycosylation of extracellular proteins do not only have a direct impact on cell growth and survival, but also facilitate tumor-induced immunomodulation, and hence metastasis (33). It has been demonstrated that $\mathrm{N}$-linked deglycosylation inhibits the growth of several types of cancer cells (25). Oncogenic roles for $\mathrm{N}$-glycans on the cancer cell surface have been described in breast cancer, colon cancer, prostate cancer, lung cancer, hepatocellular carcinoma and gastric cancer (15,34-39). Human PTX3 contains a single $\mathrm{N}$-glycosylation site that is fully occupied by complex oligosaccharides (7). The glycosylation of PTX3 has been suggested to modulate PTX3 function during inflammation and tumor development. Chi et al reported that the glycosylation of PTX3 at Asn-220 was critical for its pro-tumor involvement (18). Our results demonstrated that tunicamycin (TM), which blocked N-glycan precursor biosynthesis, enhanced the suppressive effects of Cis on lung cancer cell proliferation and migration. TM and dePTX3 also increased the suppressive effects of Cis on lung cancer cell growth, migration and invasion compared to treatment with the individual drugs. The inhibition of N-linked glycosylation biosynthetic pathways may provide a novel diagnostic and therapeutic target for cancer growth.

Cis is widely used as a chemotherapeutic drug in a number of cancer treatments, and limited by acquired or intrinsic resistance of cells to the drug $(40,41)$. Poor sensitivity to Cis is based on several mechanisms, including diminished intracellular drug accumulation due to drug efflux or metabolic inactivation, the inhibition of apoptosis, and improved DNA damage repair in cancer cells (42). The elevated expression of cell surface N-linked glycosylation has been reported to be associated with drug resistance, and the inhibition of $\mathrm{N}$-linked glycosylation in breast cancer results in an elevated sensitivity to doxorubicin (43-45). It has also been found that the TM-induced inhibition of N-linked glycosylation enhances the susceptibility of the multidrug-resistant ovarian cancer cells, to vincristine, doxorubicin, and Cis (46). The increased apoptosis of breast cancer cells has been reported following combined treatment with Herceptin and TM (45). Similarly, an enhanced sensitivity to $C$ is has been reported in head and neck cancer following TM treatment (47). In this study, we found that Cis treatment increased the expression of PTX3 in lung cancer cells, which was associated with a reduced potency of its anticancer effects on lung cancer. However, the deglycosylation of PTX3 by TM in lung cancer cells functions synergistically with Cis. This study demonstrates that alterations in PTX3 glycosylation lead to a recovery of Cis chemosensitivity with respect to the suppression of lung cancer growth and migration. To date there are limited studies available on the role of dePTX3 in cancer therapy; this warrants further investigation to elucidate the mechanisms through PTX3 glycosylation in cancer cells that is associated with a chemosensitivity to treatment.

In this study, we found that combined treatment with TM and $C$ is inhibited the survival and growth of lung cancer cells, indicating that PTX3 deglycosylation decreased the resistance of cancer cells to chemotherapeutic drugs. We further confirmed that the deglycosylation of PTX3 inactivated $\mathrm{AKT} / \mathrm{NF}-\kappa \mathrm{B}$ signaling pathway. These results reveal that the induction of PTX3 deglycosylation by TM inhibited AKT/ $\mathrm{NF}-\kappa \mathrm{B}$ pathway and contributed to prevent NF- $\kappa \mathrm{B}$-associated tumor metastasis. In lung cancer, the inhibition of $\mathrm{NF}-\kappa \mathrm{B}$ nuclear translocation also enhances apoptosis (48). The findings of this study were consistent with those of the previous studies. TM and $\mathrm{C}$ is treatment reduced AKT activation and inhibited $\mathrm{NF}-\kappa \mathrm{B}$ phosphorylation, leading to the induction 
of apoptosis and decreasing lung cancer cell growth, which resulted in the reduction of the distinct survival pathways, $\mathrm{AKT} / \mathrm{NF}-\kappa \mathrm{B}$. These results suggest that PTX3 secretion may be detrimental to the chemotherapeutic efficacy of Cis in lung cancer treatment; however, dePTX3 augments the efficacy of $\mathrm{Cis}$ by inhibiting the activation of $\mathrm{AKT} / \mathrm{NF}-\kappa \mathrm{B}$ in lung cancer.

In conclusion, the findings of this study suggest that the deglycosylation of PTX3 by TM significantly sensitizes lung cancer cells to Cis, and impairs cell growth and metastasis. Our preliminary results also suggest that the manipulation of $\mathrm{N}$-linked glycosylation of PTX3 by TM in tumor cells may prove to be a useful therapeutic strategy for successful chemotherapy in combination with $\mathrm{Cis}$ against lung cancer or other solid cancers.

\section{Acknowledgements}

Not applicable.

\section{Funding}

This study was supported by the National Natural Science Foundation of China Research Grants (nos. 31670810,31870794, 81572881).

\section{Availability of data and materials}

The datasets used and/or analyzed during the current study are available from the corresponding author on reasonable request.

\section{Authors' contributions}

BA and QY conceived and designed the study with inputs from MNK. QY and BA were responsible for the supervision and coordination of the project. BA, MNK, SK and MAN performed most of the in vitro experiments. BA led the data analysis with inputs from QY, MNK, QZ, YL and SK. BA and YL performed statistical analysis of the data. The first draft of the manuscript was written by BA and MNK then QY, MNK, SK, YL and MAN contributed to revise and review the manuscript. All authors read and approved the final manuscript before submission.

\section{Ethics approval and consent to participate}

The use of human lung cancer serum and tissue was reviewed and approved by the Ethics Committee of Dalian Medical University, and was performed in accordance with the approved guidelines. Informed consent was obtained from lung cancer patients and samples were obtained from the First Affiliated Hospital of Dalian Medical University.

\section{Patient consent for publication}

Not applicable.

\section{Competing interests}

The authors declare that they have no competing interests.

\section{References}

1. O'Byrne KJ, Barr MP and Gray SG: The role of epigenetics in resistance to Cisplatin chemotherapy in lung cancer. Cancers (Basel) 3: 1426-1453, 2011.

2. Zhuang H, Jiang W, Zhang X, Qiu F, Gan Z, Cheng W, Zhang J, Guan S, Tang B, Huang Q, et al: Suppression of HSP70 expression sensitizes NSCLC cell lines to TRAIL-induced apoptosis by upregulating DR4 and DR5 and downregulating c-FLIP-L expressions. J Mol Med (Berl) 91: 219-235, 2013.

3. Lv XB, Liu L, Cheng C, Yu B, Xiong L, Hu K, Tang J, Zeng L and Sang Y: SUN2 exerts tumor suppressor functions by suppressing the Warburg effect in lung cancer. Sci Rep 5: 17940, 2015.

4. Boulikas T: Molecular mechanisms of cisplatin and its liposomally encapsulated form, Lipoplatin. Lipoplatin as a chemotherapy and antiangiogenesis drug. Cancer Biol Ther 5: 351-376, 2007.

5. Lin Y, Wang Z, Liu L and Chen L: Akt is the downstream target of GRP78 in mediating cisplatin resistance in ER stress-tolerant human lung cancer cells. Lung Cancer 71: 291-297, 2011.

6. Fuertes MA, Alonso C and Pérez JM: Biochemical modulation of cisplatin mechanisms of action: Enhancement of antitumor activity and circumvention of drug resistance. Chem Rev 103: 645-662, 2003.

7. Bottazzi B, Inforzato A, Messa M, Barbagallo M, Magrini E, Garlanda $C$ and Mantovani A: The pentraxins PTX3 and SAP in innate immunity, regulation of inflammation and tissue remodelling. J Hepatol 64: 1416-1427, 2016.

8. Balhara J, Koussih L, Zhang J and Gounni AS: Pentraxin 3: An immuno-regulator in the lungs. Front Immunol 4: 127, 2013.

9. Inforzato A, Rivieccio V, Morreale AP, Bastone A, Salustri A, Scarchilli L, Verdoliva A, Vincenti S, Gallo G, Chiapparino C, et al: Structural characterization of PTX3 disulfide bond network and its multimeric status in cumulus matrix organization. J Biol Chem 283: 10147-10161, 2008.

10. Inforzato A, Reading PC, Barbati E, Bottazzi B, Garlanda C and Mantovani A: The 'sweet' side of a long pentraxin: How glycosylation affects PTX3 functions in innate immunity and inflammation. Front Immunol 3: 407, 2013.

11. EL-Attar HA, Abaza MM, Gaber EW and EL-sharkawy RM: Serum profiles of pentraxin-3 and high sensitivity $C$ - reactive protein in patients with chronic kidney disease treated with or without hemodialysis. J Nephrol Ther 7: 1, 2017.

12. Locatelli M, Ferrero S, Martinelli Boneschi F, Boiocchi L, Zavanone M, Maria Gaini S, Bello L, Valentino S, Barbati E, Nebuloni M, et al: The long pentraxin PTX3 as a correlate of cancer-related inflammation and prognosis of malignancy in gliomas. J Neuroimmunol 260: 99-106, 2013.

13. Willeke F, Assad A, Findeisen P, Schromm E, Grobholz R, von Gerstenbergk B, Mantovani A, Peri S, Friess HH, Post S, et al: Overexpression of a member of the pentraxin family (PTX3) in human soft tissue liposarcoma. Eur J Cancer 42: 2639-2646, 2006.

14. Stallone G, Cormio L, Netti GS, Infante B, Selvaggio O, Fino GD, Ranieri E, Bruno F, Prattichizzo C, Sanguedolce F, et al: Pentraxin 3: A novel biomarker for predicting progression from prostatic inflammation to prostate cancer. Cancer Res 74: 4230-4238, 2014.

15. Diamandis EP, Goodglick L, Planque $\mathrm{C}$ and Thornquist MD: Pentraxin-3 is a novel biomarker of lung carcinoma. Clin Cancer Res 17: 2395-2399, 2011.

16. Choi B, Lee EJ, Song DH, Yoon SC, Chung YH, Jang Y, Kim SM, Song Y, Kang SW, Yoon SY, et al: Elevated Pentraxin 3 in bone metastatic breast cancer is correlated with osteolytic function. Oncotarget 5: 481-492, 2014.

17. Argani H, Ghorbanihaghjo A, Panahi G, Rashtchizadeh N, Safa J and Meimand SM: Serum Fetuin-A and Pentraxin3 in hemodialysis and renal transplant patients. Clin Biochem 45: 775-779, 2012.

18. Chi JY, Hsiao YW, Li CF, Lo YC, Lin ZY, Hong JY, Liu YM, Han X, Wang SM, Chen BK, et al: Targeting chemotherapy-induced PTX3 in tumor stroma to prevent the progression of drug-resistant cancers. Oncotarget 6: 23987-24001, 2015

19. Vasconcelos-Dos-Santos A, Oliveira IA, Lucena MC, Mantuano NR, Whelan SA, Dias WB and Todeschini AR: Biosynthetic machinery involved in aberrant glycosylation: Promising targets for developing of drugs against cancer. Front Oncol 5: 138, 2015. 
20. Song EY, Kang SK, Lee YC, Park YG, Chung TH, Kwon DH, Byun SM and Kim CH: Expression of bisecting $\mathrm{N}$-acetylglucosaminyltransferase-III in human hepatocarcinoma tissues, fetal liver tissues, and hepatoma cell lines of Hep3B and HepG2. Cancer Invest 19: 799-807, 2001.

21. Mori S, Aoyagi Y, Yanagi M, Suzuki Y and Asakura H: Serum $\mathrm{N}$-acetylglucosaminyltransferase III activities in hepatocellular carcinoma. J Gastroenterol Hepatol 13: 610-619, 1998.

22. Dube DH and Bertozzi CR: Glycans in cancer and inflammation - potential for therapeutics and diagnostics. Nat Rev Drug Discov 4: 477-488, 2005.

23. Chatterjee BP, Mondal G and Chatterjee U: Glycosylation of acute phase proteins: A promising disease biomarker. Proc Nat Acad Sci, India - Sect B: Biol Sci 84: 865-874, 2014.

24. Reticker-Flynn NE and Bhatia SN: Aberrant glycosylation promotes lung cancer metastasis through adhesion to galectins in the metastatic niche. Cancer Discov 5: 168-181, 2015.

25. Contessa JN, Bhojani MS, Freeze HH, Rehemtulla A and Lawrence TS: Inhibition of N-linked glycosylation disrupts receptor tyrosine kinase signaling in tumor cells. Cancer Res 68: 3803-3809, 2008.

26. de Freitas Junior JCM and Morgado-Díaz JA: The role of $\mathrm{N}$-glycans in colorectal cancer progression: Potential biomarkers and therapeutic applications. Oncotarget 7: 19395-19413, 2016.

27. Han X, Zhang X, Li H, Huang S, Zhang S, Wang F and Shi Y: Tunicamycin enhances the antitumor activity of trastuzumab on breast cancer in vitro and in vivo. Oncotarget 6: 38912-38925, 2015.

28. Ahsan A, Hiniker SM, Ramanand SG, Nyati S, Hegde A,Helman A Menawat R, Bhojani MS, Lawrence TS and Nyati MK: Role of epidermal growth factor receptor degradation in cisplatin-induced cytotoxicity in head and neck cancer. Cancer Res 70: 2862-2869, 2010.

29. Banerjee A, Lang JY, Hung MC, Sengupta K, Banerjee SK Baksi $\mathrm{K}$ and Banerjee DK: Unfolded protein response is required in $\mathrm{nu} / \mathrm{nu}$ mice microvasculature for treating breast tumor with tunicamycin. J Biol Chem 286: 29127-29138, 2011.

30. Planque C, Kulasingam V, Smith CR, Reckamp K, Goodglick L and Diamandis EP: Identification of five candidate lung cancer biomarkers by proteomics analysis of conditioned media of four lung cancer cell lines. Mol Cell Proteomics 8: 2746-2758, 2009.

31. Kondo S, Ueno H, Hosoi H, Hashimoto J, Morizane C, Koizumi F, Tamura K and Okusaka T: Clinical impact of pentraxin family expression on prognosis of pancreatic carcinoma. Br J Cancer 109: 739-746, 2013

32. O'Connor SE and Imperiali B: Modulation of protein structure and function by asparagine-linked glycosylation. Chem Biol 3: 803-812, 1996

33. Häuselmann I and Borsig L: Altered tumor-cell glycosylation promotes metastasis. Front Oncol 4: 28, 2014.

34. Kudo T, Nakagawa H, Takahashi M, Hamaguchi J, Kamiyama N, Yokoo H, Nakanishi K, Nakagawa T, Kamiyama T, Deguchi K, et al: N-glycan alterations are associated with drug resistance in human hepatocellular carcinoma. Mol Cancer 6: 32, 2007.

35. Tafani M, Russo A, Di Vito M, Sale P, Pellegrini L, Schito L, Gentileschi S, Bracaglia R, Marandino F, Garaci E, et al: Up-regulation of pro-inflammatory genes as adaptation to hypoxia in MCF-7 cells and in human mammary invasive carcinoma microenvironment. Cancer Sci 101: 1014-1023, 2010.
36. Li WP, Zuber C, Heitz PU and Roth J: Cytochemical staining for beta 1,6 branching of asparagine-linked oligosaccharides in variants of metastatic human colon carcinoma cells. Am J Pathol 145: 470-480, 1994.

37. Saldova R, Fan Y, Fitzpatrick JM, Watson RW and Rudd PM Core fucosylation and alpha2-3 sialylation in serum $\mathrm{N}$-glycome is significantly increased in prostate cancer comparing to benign prostate hyperplasia. Glycobiology 21: 195-205, 2011.

38. Liu L, Yan B, Huang J, Gu Q, Wang L, Fang M, Jiao J and Yue X: The identification and characterization of novel N-glycan-based biomarkers in gastric cancer. PLoS One 8: e77821,2013.

39. Saldova R, Reuben JM, Abd Hamid UM, Rudd PM and Cristofanilli M: Levels of specific serum N-glycans identify breast cancer patients with higher circulating tumor cell counts. Ann Oncol 22: 1113-1119, 2011

40. Li L, Khan MN, Li Q, Chen X, Wei J, Wang B, Cheng JW, Gordon JR and Li F: G31P, CXCR1/2 inhibitor, with cisplatin inhibits the growth of mice hepatocellular carcinoma and mitigates high dose cisplatin-induced nephrotoxicity. Oncol Rep 33: 751-757, 2015.

41. Dasari S and Tchounwou PB: Cisplatin in cancer therapy: Molecular mechanisms of action. Eur J Pharmacol 740: 364-378, 2014.

42. Tanida S, Mizoshita T, Ozeki K, Tsukamoto H, Kamiya T, Kataoka H, Sakamuro D and Joh T: Mechanisms of cisplatin-induced apoptosis and of cisplatin sensitivity: Potential of BIN1 to act as a potent predictor of cisplatin sensitivity in gastric cancer treatment. Int J Surg Oncol 2012: 862879, 2012.

43. Liu X, Nie H, Zhang Y, Yao Y, Maitikabili A, Qu Y, Shi S, Chen C and Li Y: Cell surface-specific N-glycan profiling in breast cancer. PLoS One 8: e72704, 2013.

44. Ferreira JA, Peixoto A, Neves M, Gaiteiro C, Reis CA, Assaraf YG and Santos LL: Mechanisms of cisplatin resistance and targeting of cancer stem cells: Adding glycosylation to the equation. Drug Resist Updat 24: 34-54, 2016.

45. Peiris D, Spector AF, Lomax-Browne H, Azimi T, Ramesh B, Loizidou M, Welch H and Dwek MV: Cellular glycosylation affects Herceptin binding and sensitivity of breast cancer cells to doxorubicin and growth factors. Sci Rep 7: 43006, 2017.

46. Hiss DC, Gabriels GA and Folb PI: Combination of tunicamycin with anticancer drugs synergistically enhances their toxicity in multidrug-resistant human ovarian cystadenocarcinoma cells. Cancer Cell Int 7: 5, 2007.

47. Noda I, Fujieda S, Seki M, Tanaka N, Sunaga H, Ohtsubo T, Tsuzuki H, Fan GK and Saito H: Inhibition of N-linked glycosylation by tunicamycin enhances sensitivity to cisplatin in human head-and-neck carcinoma cells. Int J Cancer 80: 279-284, 1999.

48. Chen W, Li Z, Bai L and Lin Y: NF-kappaB, a mediator for lung carcinogenesis and a target for lung cancer prevention and therapy. Front Biosci 16: 1172-1185, 2011.

This work is licensed under a Creative Commons Attribution-NonCommercial-NoDerivatives 4.0 International (CC BY-NC-ND 4.0) License. 